\title{
MODAL LOGIC IN SIXTEENTH-CENTURY MEXICO
}

WALTER REDMOND

Universidad Autónoma de Pueble

We present here some tentative notes on modal logic in the Recognitio Summularum of Alonso Gutiérrez de la Vera Cruz (1504-1584). 1 The sortal language $L$ previously suggested in this journal will be expanded to parallel Fray Alonso's approach, and then his own exposition will be discussed.2

\section{MODAL LOGIC}

\section{A. Expansion of $L$}

The extension of $\mathrm{L}$ is as follows (see c.45). Lower-case letters, generally suggesting the reference, will be used both as proper names, that is, "determined (singular) terms" (26B, c.56), and as abbreviations of definite descriptions; e.g., "j[w]" ("John walks"), "f[d]" ("the Father is a divine Person"). 3 Letters used as sortal constants and variables (c.45-6) may be employed without subscript or quantification as

1 We heve inchuded material from the treatises on modal sentences, supposition and ascent/descent, ampliation, restriction, appellation, signification and intentionality of terms, chapter 10 in the section on sentences and chapters 19-20, 22, $23,24-5,7$, and 8 in the section on terms respectively of the 1573 Salamanca edition, to which we refer by citing page and column. A Spanish translation of the chapter on modal sentences has appeared as " 'Sobre las oraciones modales' por Fray Alonso" in Revista de Filosofia, Universidad Iberoamericana (Mexico City). "Tentative" because these comments are based only on the friar's somewhat sketchy account of a complex discussion, a throughgoing investigation of which is called for. We attempt no clarification of such present-day issues as transworld identity also present in Alonso's account of modal logic.

2 Crítica, vol. xiii, no. 39, México, Dec. $1981,45-73$; we refer to this article with a "c." followed by the page number.

$3 j[w] \equiv[w] j$, but, with Alonso, we generally prefer the left-hand coimplicate. 
proper names of corresponding conceptual entities; e.g., "h[s]" ("man is a species") but " $\mathrm{j}[\mathrm{h}]$ " ("John is a man"). 4

Terms enclosed in single quotation marks and followed by a numerical subscript will be used as "vague (singular) terms" (26B, c.56) to denote themselves as tokens (or to denote other tokens) of their types; e.g., " " $h_{1}{ }_{1}[t]$ " ("this ' $h_{1}$ ' is a term"), " " $h{ }_{1}$ [t]" ("this ' $h$ ' is a term"). Terms marked off by quotation marks and enclosed in a quantifier will be used without subscript as variables ranging over tokens, including themselves, of their types; e.g., "( $\left.h_{1}\right)[t]$ " ("every ' $h_{1}$ ' is a term"), "[ $h$ ']/(t)" ("some ' $h$ ' is not a term").

Sentences enclosed in single quotation marks followed by a numerical subscript will be used as vague terms denoting themselves as tokens (or denoting other tokens) of their types; e.g., " " $j[w]$ ' ${ }_{1}[t]$ " ("this 'John walks' is a term"). Sentences marked off by quotation marks and enclosed in a quantifier will be used without subscript as variables ranging over tokens, including themselves, of their types; e.g. " $[j[w]$ " $] /(t)$ " ("some ' $j[w]$ ' is not a term"). Sentences marked off by periods will be used as proper names in the sense of determined terms of the propositions they express; e.g., ".j[w] • [i]" ("that John walks is incredible"). 5

" $n$ " and "p" are (term) variables ranging over necessities and possibilities (whose meaning is explained below) respectively, and with numerical subscripts they are taken as (individual) constants or vague terms standing for individual necessities and possibilities. "n" and " $p$ " will also be used as modal operators indicating necessity and possibility respectively. " $n$ " and " $p$ ", whether functioning as units (c. 46) or operators, are called "modes". 6

4 Alternately, instead of a proper name or determined term, the letter, perhape capitalized, could be used as a constant or vague term and variable to denote and range over the (single) conceptual entity. In this case, because the analysis is the same, $\mathrm{H}_{1}[\mathrm{~s}] \equiv(\mathrm{H})[\mathrm{s}] \equiv[\mathrm{H}][\mathrm{s}]$. For Alonso, in personal, discrete supposition (c.60) the singular term may be either determined or vague.

5 Alternatively, a sentence could be used as a vague term with numerical subecript and a variable with a quantifier to denote or range over the (single) proposition it expresses. In this case, $j[w]_{1}[i] \equiv(j[w])[i] \equiv[j[w]][i]$, because the analysis is the seme.

6 Since Alonso's modal logic is allied to tense logic, a tense symbolism could he added to $\mathrm{L}$ to portray the relation. 
Thus if $S$ is a sentence used as a unit and $M$ a mode used as a unit, SM is a sentence. 7 This kind of modal sentence is called "composite" or "de dicto", and the contained sentence is called the "dictum" of SM. For example, ".j[w] . [p]" may be read "for John to walk is possible", "it is possible that John walk," "John can walk", or more precisely "for John to be identical with some walking thing is identical to some possibility"; here " $j[w]$ " is the dictum and " $p$ " the (quantified) mode. " $f[d]$ ' ${ }_{1}[n]$ " may be read " $f[d]$ ' is a (sentence expressing) necessity."

If $U$ and $W$ are units and $M$ a modal operator, then $U M W$ is a sentence.8 This kind of modal sentence is called "divided" or "de re." and $\mathrm{UW}$ is called the "dictum" of UMW. Thus "jp[w]" may be read "John possibly walks," "John can walk," or even "John is identical to something possibly running"; here " $j[w]$ " is the dictum and " $p$ " the mode.

\section{B. Sentential Relations}

Negation (c. 46) is combined with modality to yield the usual equivalences:

$$
\begin{array}{lc}
\text { Divided sentences } & \text { Composite sentences } \\
\mathrm{UnW} \equiv \mathrm{U} / \mathrm{p} / \mathrm{W} & . \mathrm{UW} .[\mathrm{n}] \equiv . \mathrm{U} / \mathrm{W} . /(\mathrm{p}) \\
\mathrm{U} / \mathrm{nW} \equiv \mathrm{Up} / \mathrm{W} & . \mathrm{UW} . /(\mathrm{n}) \equiv . \mathrm{U} / \mathrm{W} .[\mathrm{p}] \\
\mathrm{Un} / \mathrm{W} \equiv \mathrm{U} / \mathrm{pW} & . \mathrm{U} / \mathrm{W} .[\mathrm{n}] \equiv . \mathrm{UW} . /(\mathrm{p}) \\
\mathrm{U} / \mathrm{n} / \mathrm{W} \equiv \mathrm{UpW} & . \mathrm{U} / \mathrm{W} . /(\mathrm{n}) \equiv . \mathrm{UW} .[\mathrm{p}]
\end{array}
$$

7 For Alonso sentences of the form SM would be equivalent to MS except in some cases where the dictum is quantified, but he urges $(67 \mathrm{~B} 68 \mathrm{~A})$ standardization by always making the mode the predicate, and he follows his own rule.

8 All of Vera Cruz's examples are of the UMW type, but he allows MUW (70AB). To preserve equivalence in conversion, among other things, the modal operator must govern the same unit; e.g. gnlc] $\equiv$ n[c]g ("God necesearily creates"); He gives no "iterated modalities" like ". $j[w] .[p] .[p]$, , "jp[w].[p]," "j[w].p[p]," etc. 
Another set of equivalences for composite sentences can be formed in which quotation marks replace the periods. ${ }^{9}$ For example, " $\mathrm{j} / \mathrm{n}(\mathrm{w})$ " may be read as "John does not necessarily walk", ".j[w]./(n)" as "for John to walk is not necessary," "it is not necessary that John walk," ".g/(c).[p]" as "for God not to create is possible," " $\mathrm{g}[\mathrm{c}]$ ", $/(\mathrm{n})$ " as "this ' $g[c]$ ' is not necessary," and ".(b)[r]./(n) $\equiv .[b] /(r) .[p] "$ as "for every bicycle-rider or cyclist to be rational is not necessary if and only if for some cyclist not to be rational is possible".

The ascent and descent rules (c.5lff) apply to sentence allowed in expanded L. For example: ${ }^{10}$

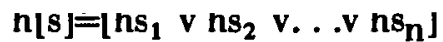

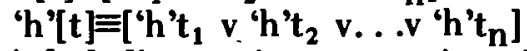

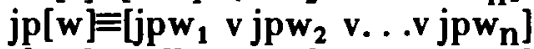

(b) $n[r] \equiv\left[\left[b_{1} n r_{1} \quad v^{2} b_{1} n r_{2} \quad v \ldots . \quad \ldots b_{1} n r_{n}\right] \&\right.$

$\left[b_{2} n r_{1} v b_{2} n r_{2} v \ldots . v b_{2} n r_{n}\right] \& . . \&$

$\left.\left[b_{n} n_{1} v b_{n} n_{2} v . . v b_{n} n_{n}\right]\right]$.

The "apply-at-the-left" rule $(c .51,65)$ is in effect here, and the dictum of a composite modal sentence is of course treated as a term in these operations:

$. j[w] .[p] \equiv\left[. j[w] . p_{1} \quad v . j[w] . p_{2} \quad v \ldots . v . \quad . j[w] . p_{n}\right]$

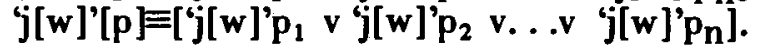

However, since a general sentence is taken as equivalent to its analysis, the analysis of the dictum could replace the general form; e.g.:

$$
\begin{array}{r}
. f[d] .[n] \equiv\left[. f d_{1} v \text { fd }_{2} v \text { fd }_{3} \cdot n_{1}\right. \\
v . \text { fd }_{1} v \text { fd }_{2} v \text { fd }_{3} \cdot n_{2} \\
\left.v \text { fd }_{1} v \text { fd }_{2} v \text { fd }_{3} \cdot n_{n}\right] .
\end{array}
$$

9 As in the case of the standard categoricals, the quantification of the predicate of modal sentences follows the quality (c.57) of the whole sentence. However, nonstandard modal sentences could be produced, e.g., the $R^{*}$ forms (c.48) " $[a \mid p(h)$ " ("Some animal can be every man") and " $[p](j[w]$ ")" ("some possibility is every ' $\mathrm{j}[\mathrm{w}]^{\prime}$ ").

10 For the supposed equivalence between a general sentence and its analysis see c.54, 67-69. 
The following schema shows relations of entailment (arrows) and contradiction (lines between columns) among composite sentences whose dicta consist of a singular and general term:

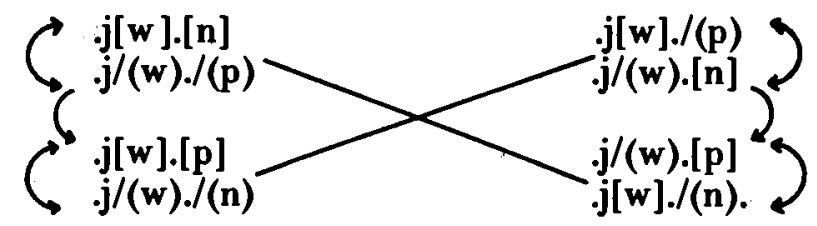

The relations of contrariety and subcontrariety hold here:

$. j[w] .[n] \mid . j /(w) .[n]$

$. j /(w) . /(n) v . j /(w) \cdot[p]$.

This is the corresponding schema for divided sentences:

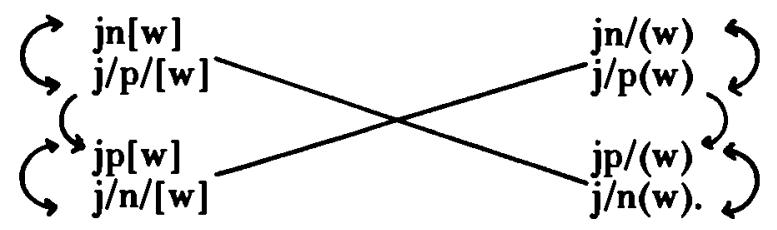

The sentence forms in the following schema differ in quantification and quality of the dicta and type and quality (and hence quantification, since standard) of the modes, and assertoric forms have been included: 


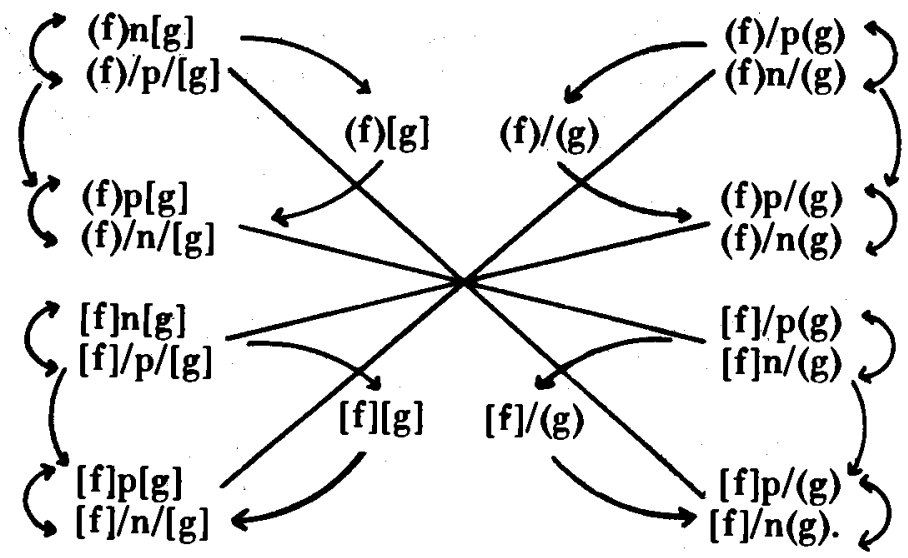

C. Semantics

First we present the assertoric semantics of personal, material, and simple supposition (see c. 59-60).

The following diagram sketches the reference of the terms of the true disjunct, say " $\mathrm{ja}_{1}$ " of " $\mathrm{j}[\mathrm{a}]$ " ("John is an animal"). The curved arch indicates property entailment or class inclusion (H c A), the straight arch indicates posession of a property or class membership $(j \in H, j \in A$ ), and the arrows simbolize the semantic reference of the terms.

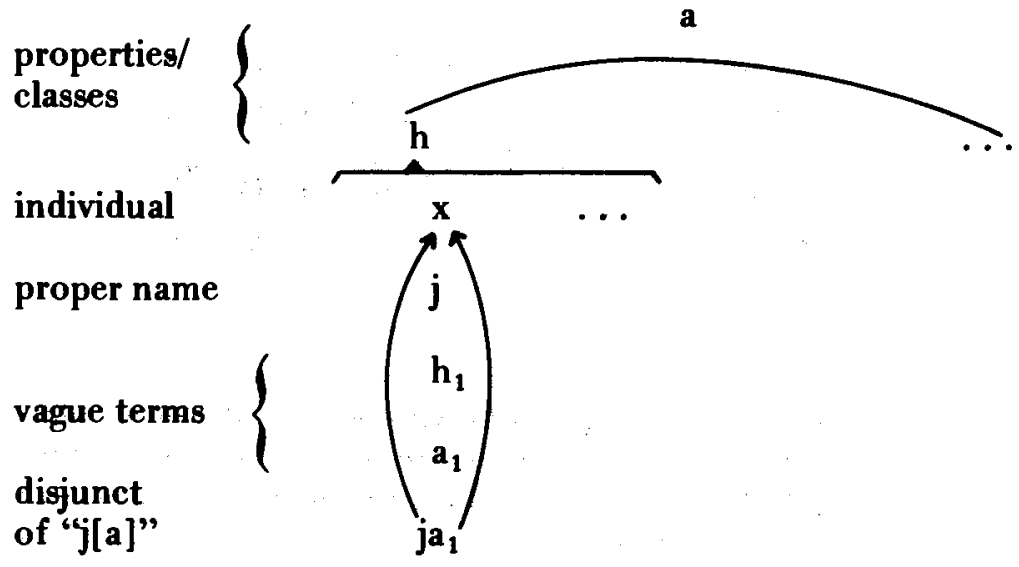


This is a diagram of a true disjunct of " " $h$ ' ${ }_{1}$ [t]", say " ' $h$ ' $t_{1}$ ", where " $h$ ' " indicates that "this " $h$ ' " is to be taken for itself:

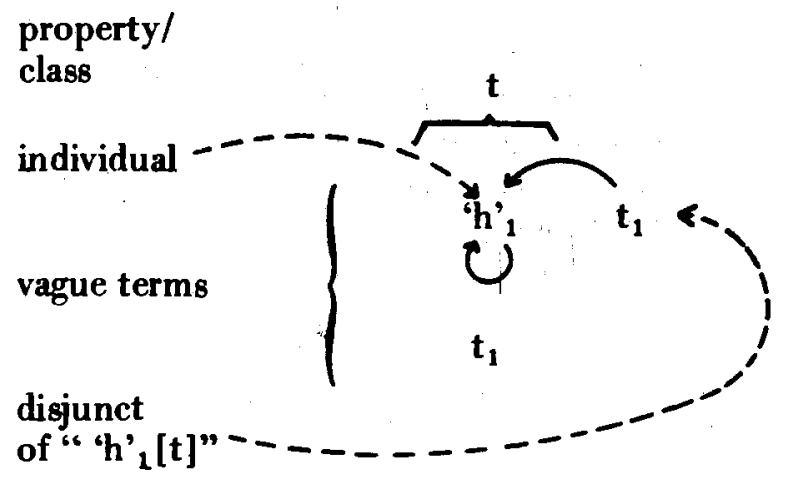

This diagram represents a true disjunct of " $h[s]$ ", say " $j s_{1}$ " ("u" here means "being a universal"):

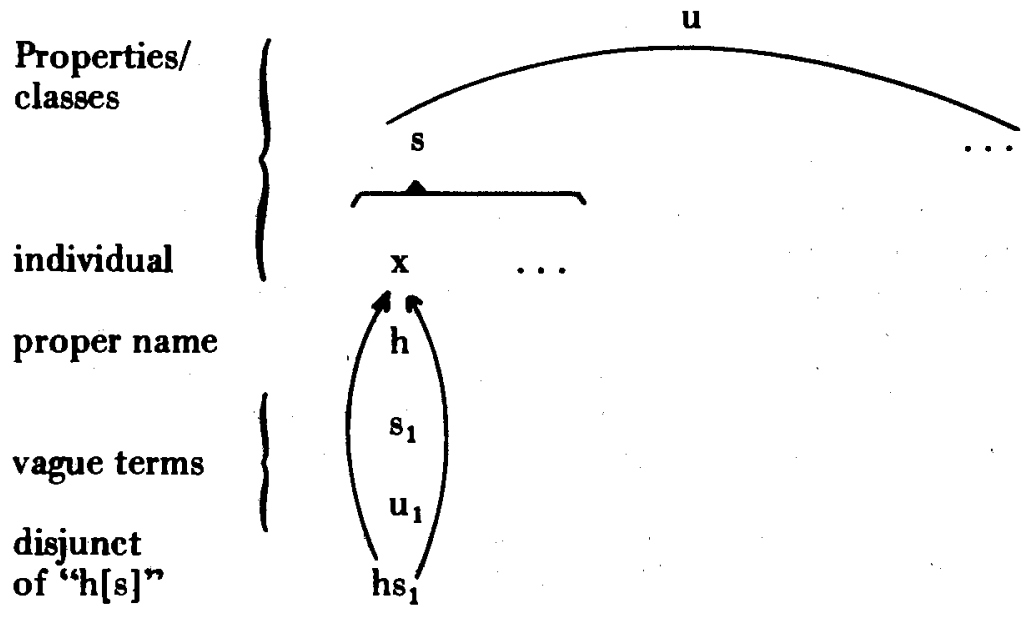


Alonso gives what amounts to a linguistic and an objectual (in a wide sense) or extralinguistic interpretation of composit modal sentences, corresponding to the two ways of setting off the dictum: by quotation marks of by periods. The interpretation is linguistic if the dictum is taken to refer to itself as a token (or to another token) of the sentence type of which it is a token, and the mode is taken as a predicate of the sentence constituting the dictum. The reference of the

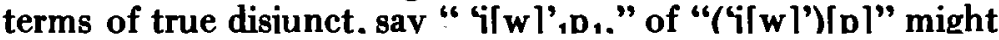

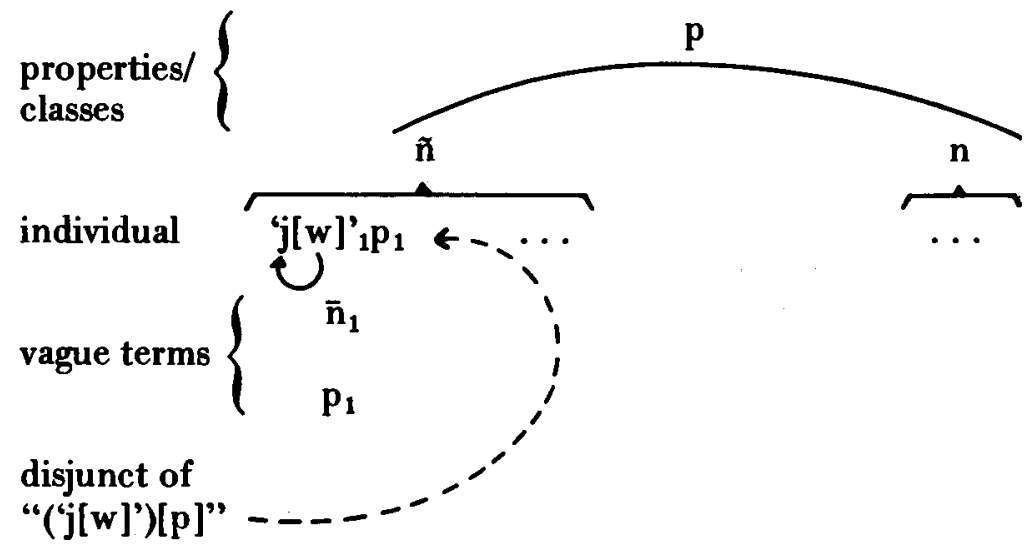

Here "p" means something like "being a sentence express. ing (the) possibility," " $n$ ", "being a sentence expressing (the) necessity", and " $\vec{n}$ ", with " $p$ ", "being a sentence expressing (the) contingency".11

The interpretation is objectual if the dictum is taken to refer to a proposition and the mode is taken as a predicate of the proposition. The following diagram displays the reference

11 "p" of course does not mean "being a problematic sentence" (since the dictum is not modal) nor "being a poseible sentence." But there are several ways of interpreting " $p$ " and " $n$ " linguistically. 
of the terms of true disjuncts, say ".(b) $[r] . p_{1}$ " and ".(m) [r]..n of ".(b) [r].[p]" and ".(m) [r].[n]" respectively. Here "p" and " $n$ " have a more basic meaning of being a possibility or necessity, that is, "possible" and "necessary" as said of propositions.

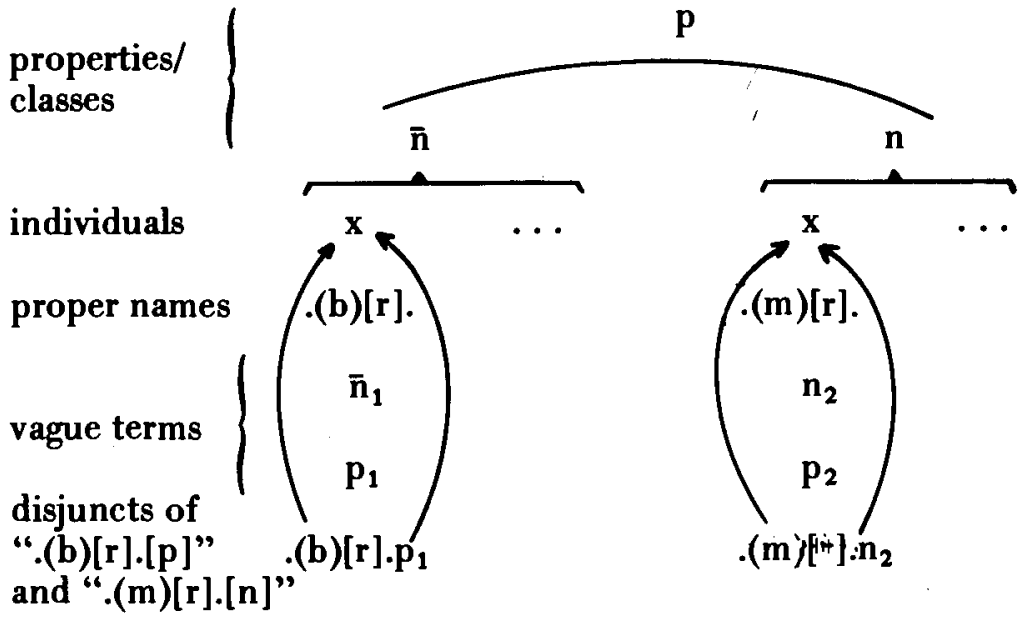

The objectual interpretation is basic, but once the sentence in question is presupposed, we have an equivalence:

$$
. j[w] .[p] \equiv j[w]_{1}[p],
$$

that is, "for John to walk is possible if and only if this sentence 'John walks' is possible," where "possible" has two meanings defined by context.

Fray Alonso only gives an objectual interpretation of the divided modal sentence. Here we must separate the reference of the terms of the sentence, because the modal operator governs only the following term. In the normal UMW form, the reference of the subject is context specific but that of the predicate is to possibilities or necessities. Since the modality is embedded in the singular sentences of the analysis of the modal sentence, a series of true disjuncts (sometimes of con- 
juncts) must be represented. The following diagrams simbolize the reference of "[u]p[e]" ("someone foreknown by God as unsaved is elect, saved") and "( $(\mathrm{m}) \mathrm{n}[\mathrm{r}]$," whose true singular sentences are, say, " $u_{1} p_{1}$ ", " $u_{2} p e_{2}$ ", etc. and " $m_{1} n r_{1}$ ", " $_{2} \mathrm{nr}_{2}$ ", etc. respectively. The dotted lines symbolize that the individuals are the same in distinct referential contexts. Presumibly, the specific context implied by the subject is one, and while possible contexts may differ (indicated by the broken line), the necessary reference may be taken as one.
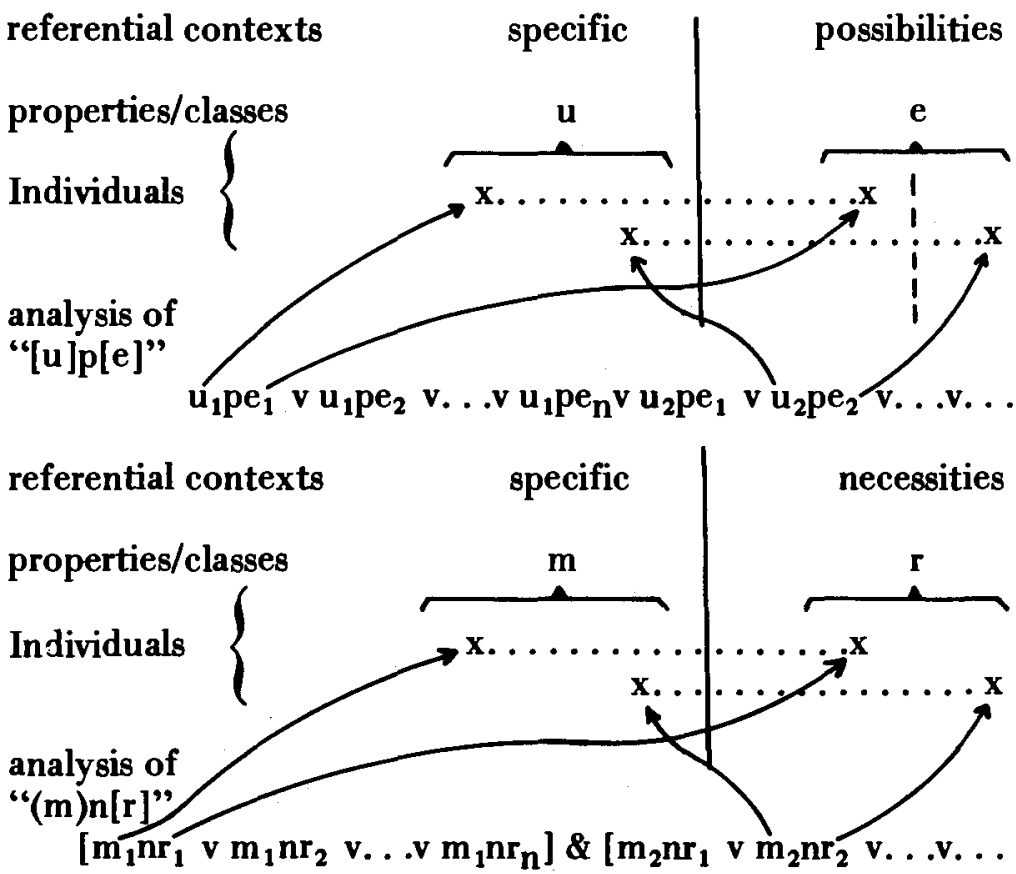

A common way of formalizing modal sentences like ".(m)[r].[n]" and "(m)n[r]" is " $\square(x)[M x \supset R x] "$ and “( $(\mathrm{x})[\mathrm{Mx} \supset \square \mathrm{Rx}]$ " respectively. Plantinga thinks, pace Quine, 
that the divided form is unacceptable for the essentialist.12 Of ".[u][e].[p]" and "[u]p[e]", usually formalized as " $\diamond(\exists x)$ [Ux \& Ex]" and " $(\exists x)$ [Ux \& $\diamond$ Ex]" respectively, Alonso thinks the composite version is false but the divided one true, since, as we might say, something known by god to be unsaved and hence unsaved in, say, the actual world, is elect in some (other) possible world.

\section{ALONSO'S APPROACH TO MODAL LOGIC}

The foregoing presentation of modal logic probably represents fairly the friar's conception. We now consider how he treats these matters, closely following his own language.

\section{A. Extensionality and Modality}

Fray Alonso's modal logic is traditional, but he is required to take sides on several points which were discussed in his time. He begins his chapter on modal sentences with a quote from the Summulae Logicales of Peter of Spain (63B65B), who distinguishes an adverbial and a "nominal" way of expressing modality. Alonso accepts (69A) possibility and necessity as the basic modes and uses the two kinds of expression to distinguish syntactically between composite and divided modality: "Petrum disputare est possibile" and 'Petrus possibiliter disputat," a familiar approach in scholastic logic. He uses the traditional term "de inesse" for non-modal sentences; we have translated it "assertoric," but he uses it also in a stricter sense of "non-modal and not tensed in past or future" (70B). He notes (66B) the parallelism between quantification and modality, pairing "necessary" with "every" and "possible" with "some." He also, with the tradition, relates (68B) to modal words epistemic terms like "opinable," "imaginable," "understandable," etc., and claims "true" and

12 A. Plantinga, The Nature of Necescity, Oxford, 1974, p. 25, referring to W. Quine, Word and Object, M.I.T. Press, 1960 , p. 199. 
"false" are not, strictly speaking, modal predicates, since sentences in which they govern a "dictum" are equivalent to the latter without such modification.

An interesting feature of the modal logic of Alonso and his coleagues is their apparent interpretation of modal sentences in an extensional framework of "supposition" in which they develop their yeneral sentence theorv (c.59ff).

which the sentence peter disputes" signities is something possible $(66 \mathrm{AB}){ }^{13}$ This is the objectual interpretation of a composite modal sentence, where the subject "is taken personally for the significate" (66B), that is, in personal supposition, and the predicate, "possible" is also taken "personally" and "as first intention," that is, roughly, not as a language predicate. The discussion today about "propositions" is surely wide enough to allow us to translate "significatum of a sentence" as "proposition." Alonso's view seems to be that a proposition is of a basic order and its predicates are not "of second intention."

In the case of a sentence like " $h[\mathrm{~s}]$," where the subject is a conceptual entity, Vera Cruz does say the predicate is of second intention (33AB), that is "logical, grammatical, or rhetorical" (30B). The subject, "man," has simple supposition (c. 59-60), since it refers to "the nature grasped by the understanding as one" and hence is to be taken not as universal or particular but "simply," as a singular which permits of no descent/ascent (33B, 34A, c.55). It is a question of an intentional context, because the predicate "species" "implies an act of the mind" such as defining, predicating, or understanding (33B); indeed the predicate is of higher order in the sense that being a species applies to being a man which in turn applies to Socrates. ${ }^{14}$

The linguistic interpretation of composite modal sentences

13 Itaque census hujus propositionis, Petrum disputare est posibile, est: id quod significat illa propositio, Petrus disputat, est quid poesibile.

14 For a discussion of predication theory in late scholasticiam see L. Hickman, Modern Theories of Higher Level Predicates; Second Intentions in the Neuxeit, Munich, 1980. 
also involves supposition, in this case "material" (c.59); some moderns, Alonso informs us, "claim the dictum in the composite modal is to be taken materially for the sentence" (66B). In this case the predicate is "of second intention" or linguistic. ${ }^{15}$

\section{B. The Structure of the Modal Sentence and its Semantics}

"A sentence is modal in which a mode is placed," Vera Cruz states, and the only difference between a composite and divided modal sentence is that the mode is a "noun" (nomen) in the former and an adverb in the latter (66A). In the composite modal "the mode is predicated of the dictum" and is placed as predicate "to indicate that it governs [competere] the dictum as a whole" (66A). The "orderly" arrangement is for the mode to be the predicate $(67 \mathrm{~b} 68 \mathrm{~A})$. This artificality in Alonso's examples constituting his "object language", often misunderstood as inelegant Latin, is of course an effort to achieve a linguistic control we gain through the use of artifical symbols.

These "moderns" Alonso speaks of offered a linguistic interpretation of the composite modal sentence. Basic to their approach is the claim "that the dictum. . . is taken materially for the sentence" (66B). "They say the dictum can be distributed materially, taken for all synonymous sentences corresponding to it, and can be instantiated [singularizari] for itself or any of them" (66B). He gives these examples, respectively, of universal, particular, singular, and indefinite (see Prior Analytics 24A16-20) sentences representing the linguistic interpretation:

every 'Peter runs' is possible ${ }^{16}$

some 'Peter runs' is possible

this 'Peter runs' is possible

'Peter runs' is possible.

15 In the sense of "sermocinalis" referring traditionally to the trivium of logic, grammar, and rhetoric.

16 Ut hanc, omne ly Petrum currere est poseible, dicant universalem. .. 
However, the mode does not form part of the verb "to be" linking subject and predicate, but rather "its force passes to the supposition of the predicate. . by ampliating or appellating" (67A).

"Ampliation" is, like supposition (c.59), a property of terms, wherby a term's supposition or application is widened in regard to time and/or modality. The whole sentence is ampliated in the case of the composite modal, and in the divided one the mode also affects the previous term (40B). In the case of possibility the subject is opened up "to what is, was, or will be, and can be" (41A), that is, the reference is not necessarily actual but seems to be specific. Here both subject and predicate, Alonso adds, are extended "to the manner in which the real extension becomes that of a sensible thing" (40B), meaning perhaps that the individual or "supposit" is common to the various modal contexts, but that the (less universal) properties attributed to it by subject and predicate may be "separated."

In his chapter on "appellation," another property of terms regarding certain syntactical relations among words in a sentence affecting their reference (43A), Vera Cruz gives this rule: the necessity operator in a divided modal sentence "appellates the universality it expresses both for the union of the extremes and for the material [aspect] of the following term by reason of its formal [aspect]" (44B). That is, the notion of necessity affects the union of subject and predicate as far as the supposit is concerned as well as the application of the predicate to the supposit. Such an operator, he claims, "although it has the characteristic of appellating previous terms with no necessity, [appellates those] following with necessity" (41A). His example is "gn(c)," where the formal aspect, "what it is to create," applies to the individual necessarily. The proposition is false, since it implies that the individual has the predicate necessarily (thus God would not create freely), but "[c]ng" is true for Alonso, because it makes God's existence, but not his creating, necessary. ".g[c].[n]" would of course also be false for the friar.

Alonso, then, criticizes the "modern" semantics (66A) ac- 
In this interpretation the mode "is taken as second intention" (66A) "signifying that [the dictum] is a possible sentence" (66A). The sense of the first sentence above, he tells us, is "every such sentence 'Peter disputes' is possible" (66B, see $41 \mathrm{~A}){ }^{17}$

Fray Alonso rejects the idea that the dictum of a composite modal refers to the sentence, at least in the basic sense, and insists "as some claim" (69B) that

since [the dictum] is taken personally for the significate of such a sentence and the significate of synonymous sentences is said to be one and the same, it follows that every dictum of such form is understood singularly... Hence no composite modal should be universal or particular because of its dictum; rather every one is singular, or has the manner of a singular. . . (66B $)^{18}$

He clarifies a possible misunderstanding (69B) that taking the dictum as singular does not mean its significate cannot be general. We should distinguish, in other words, two senses of "the dictum is singular" as said of ".(a)[h].[p]": true in the sense that the dictum expresses a single proposition but false in the sense that the dictum is an $A^{*}$-sentence (c. 48).

The divided modal sentence "is a categorical sentence whose verb is determined by some universal or particular mode" (66A), that is, by a necessity or possibility operator. E.g., in "Petrus possibiliter disputat," the mode, an adverb, is inserted into the dictum to "denote the possibility between the thing [rem] signified by the predicate and [that signified] by the subject" (66A). However, he allows the mode to affect the subject:

The modal sentence divided by reason of its subject is to be tested and analyzed [probanda et resolvenda] in the same way as other categoricals, but by reason of its

17 . ita ut sensus primae sit: omnis talis propositio, Petrus disputat, est poscibilis.

18 Alonso takes this doctrine as Thomistic, but the opusculum on modal propositiones to which he refers is of doubtful authenticity (Busa, Index Thomis. ticus). 
mode it is to be recognized [cognoscenda] through its assertoric. (70AB)

cording to which the mode in a composite sentence is taken as a linguistic predicate and the dictum, possibly quantified, mentions a sentence, while the mode in the divided sentence "is taken for the thing [re], which is not a sentence" (66A). His argument is that

if somebody hears "for Socrates to run is possible," he does not conceive that the sentence is possible, but that the action, that is, the running, is possible for Socrates $(66 \mathrm{~A}) .^{19}$

But that he does not reject this linguistic interpretation, except as basic, is shown by his allowing the inference, which we presented above as a coimplication, from "for Peter to discuss is possible" to " 'Peter discusses' is possible" (66B).

His claim, as we have seen, is rather that in both composite and divided sentences the dictum is taken "personally and significatively" and the mode "as first intention and ampliatively" $(66 \mathrm{~A}, \mathrm{~B})$. Taking the dictum personally means taking it for what it primarily signifies (33AB, 34B; c.59-60), the proposition (it would be taking it "materially" if it were interpreted for the sentence), and taking the dictum significatively means referring it not to itself or other tokens but to what it signifies, the proposition (22A). Considering the mode a term of first intention means not taking it as a grammatical, logical, or rhetorical predicate (30b) but in this case a predicate of propositions, and attributing to the mode an ampliative function is seeing it as "widening" the modal scope of a sentence or term.

Alonso mentions only once the ascent and descent of modal sentences. He speaks of "reducing" a modal sentence to an assertoric one in the sense of "testing it through an assertoric sentence" (67B). When asked to reduce "a man

19 Nam si quis audiat Socratem currere est possible, non concipit hanc propositionem possibilem esse, sed quod actio illa, id est, cursus, sit possibilis Socrati. 
possibly is an animal," he tells us, "first I shall give the ascending [sentences] under 'man' and then I shall reduce the singular ones themselves" (67B). This seems to mean in part (we could add a previous step: " $h_{1} p_{1} v h_{1} p_{2} v \ldots v h_{1} p a_{n} v$ $h_{2} p a_{1} v h_{2} p_{2} v$...v $h_{2} p a_{n} v$..."):

$$
\begin{array}{l|l|l}
1 & h_{1} p[a] v h_{2} p[a] v \ldots v h_{n} p[a] \\
2 & {[h] p[a]} & 1 \text { DA (c. 52). }
\end{array}
$$

\section{Relations among Modal Sentences}

Fray Alonso speaks of relations among modal sentences in the context of squares of opposition. From them the equivalences relating modality and negation, going back to Aristotle (On Interpretation, 22Aff), can be read off. The first square given above is from Peter of Spain (collapsing "impossible" with "not possible" and "contingent" with "possible"). Alonso gives (69AB) us information to construct another square for composite sentences with two general terms, a part of which would be:

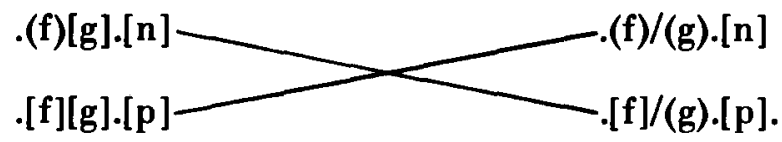

In attention to the rules, he remarks, leads to mistakes such as making both contraries true or both subcontraries false:

$$
\begin{aligned}
& .[d] f .[n] \mid .[d] / f .[n] \\
& .(d) f .[p] v .(d) / f .[p] .
\end{aligned}
$$

We included four assertoric forms (AEIO) in the more elaborate square of divided sentences above (a similar addition could be made in the others), since the moves seem to be at least partially implied in the four rules Alonso gives (42AB) for restriction, a property of terms, the converse of 
ampliation, which permits deduction of certain sentences from others on the casis of their temporal and/or modal scope. ${ }^{20}$ At any rate, the principles "from necessity to actuality to possibility" were known since the Middle Ages.

\section{Difficulties}

Fray Alonso gives us the truth conditions of modal sentences; e.g., for possibility, "for the truth of a sentence of the possible, it is sufficient and necessary that its assertoric be possible" (67B). Now, he gives the divided modal sentence as an example: " 'Peter is possibly learned' is true because its assertoric 'Peter is learned' is possible." But he does not restrict the rules to divided sentences; indeed they seem to hold for composite but not, at least without further qualification, for divided ones. His own example would be a counterinstance: "[u]p[e]" is true for him but "[u][e]" impossible, since it presumibly contains the contradictory "[e]/(e)."21

The essentialist will not accept Quine's translation "(m)n[r]," from which, along with the premises "(b)/n(r)" and " $b_{1} m_{1}$ ", the contradiction " $b_{1} n r_{1} \& b_{1} / n_{1}$ " could be derived. But he will accept the composite form ".(m)[r].[n]" as true. However, because $\mathrm{L}$ presupposes existential import even for terms in universal statements, it seems we must hold

D The first of these hastily presented rules, which also apply in tense logic, seems to be $A \therefore \diamond$, the fourth $-\diamond A \therefore-A$ (and hence $\square-A .-A$ ), while the third forbids the opposite, $-p \supset-\diamond p$.

21 This seems to make divided and composite forms equivalent when the dictum has a singular subject, although Alonso gives us this very example (" $[u] p[e]$ " and ".Ju][e].[p]") to stress that the distinction is important for ascertaining the truth of modal statements. He indeed says (67A, changing the example) that the composite forms " $j[w] .[p] "$ and " $j /(w)$. [n]" are equivalent to the divided sentences "sharing extremes" (c.56) "jp[w]" and " $\mathrm{jn} /(\mathrm{w})$ " respectively. He does distinguish hurriedly between modal sentences with a singular and a general aubject (40B41A); in the former case the reference of the subject is ampliated to inchude all times and, presumibly, the possible, and in the latter case the ampliation affects not only the times and modality but the identity of the individual or "supposit." This may mean that "Socrates can be wise" implies that it is the same Socrates who is or is not wise in different modal contex ts. If we allow the following formalization (which causes difficulties elsewhere) and relevant operaations, we have $\diamond W j \equiv(\exists x)[x=j \& \circ W x]$. 
for the necessary existence of at least one mathematician not to mention that of a cyclist (a problem avoided by the formalization " $\square(\mathrm{x})[\mathrm{Mx} \supset \mathrm{Rx}]$ " and " $-\square(\mathrm{x})[\mathrm{Cx} \supset \mathrm{Rx}]$ "). ${ }^{22}$

Behind Fray Alonso's treatise we can glimpse a lively and profund discussion which does not stand far from our modal logic and possible worlds semantics. A. Kenny has pointed out, indeed, that Luis Molina, a younger contemporary of Alonso, used the latter technique before Leibniz when speaking of "the orders of things."

22 A way of indicating empty clasecs (perhaps a zero subecript) or a distinction in types of necessity could be introduced. 


\section{RESUMEN}

En este artículo el autor examina varios puntos de la lógica modal de Alonso de la Vera Cruz (1504-1584). Lo hace u tilivando el instrumental de la lógica matemática, tal como ya lo ha hecho en otros trabajos. Se estudia el aspecto sintáctico de la lógica modal de Fray Alonso, pero sobre todo su aspecto semántico. Fn este último se destaca el carácter extensionalista del trabajo de Alonso. Finalmente, se presentan algunas dificultades que surgen en el texto analizado.

[Mauricio Beuchot] 